\title{
MEMÓRIAS DO FUTURO: a utilização de material de arquivo na arte contemporânea
}

Priscila Arantes

Priscila Arantes (PUC-SP)

\section{PARTE 1}

\section{O conceito de $\mathbf{R e} /$ Escritura:}

\section{o arquivo como dispositivo para a Re/Escritura da história}

Recentemente tive a oportunidade de assistir um documentário realizado pelo diretor chileno Patrício Guzman e apresentado em 2010 no Festival de Cannes. O documentário, que leva o nome de Nostalgia da Luz, parte de uma inusitada aproximação entre três atividades realizadas no Deserto de Atacama. Em um observatório de alta tecnologia, astrônomos investigam as estrelas em busca das origens do Universo. Nos canteiros arqueológicos, geólogos estudam os traços deixados pela pré-história. Ao mesmo tempo, um grupo de mulheres esquadrinha o solo do deserto à procura dos restos de seus familiares mortos durante a ditadura militar de Pinochet.

Apesar das buscas pelos vestígios do passado parecerem tão díspares entre si Guzman, em Nostalgia da Luz, estabelece sólidas conexões entre as estrelas, os ossos e os crânios humanos como se fossem arquivos de uma história à busca de um deciframento. História que diz respeito à formação do universo, à formação de culturas antigas bem como ao percurso social e político de um país; enfim histórias que parecem se tocar pelo desejo humano de cruzar a tênue linha do presente e entender como o passado pode ser um veículo fértil para o conhecimento de nossa história.

Se, por um lado, a temática do filme me toca especialmente por ser cidadã brasileira, filha de pais que lutaram durante a época da ditadura militar e por isto mesmo consciente de que grande parte da história envolvendo esse período 
ainda tem que ser conhecida e escrita através do acesso irrestrito aos documentos, testemunhos e arquivos relacionados às mortes e desaparecimentos de inúmeros militantes políticos, por outro sabemos que o arquivo e o documentário têm se convertido em veículo fértil de politização contemporânea da memória. Este é o caso do documentário Cabra Marcado para Morrer realizado pelo cineasta brasileiro Eduardo Coutinho que conta a vida de João Pedro Teixeira, um líder camponês da Paraíba, assassinado em 1962, fruto da perseguição aos camponeses antes mesmo da ditadura militar no Brasil. Aqui também somos levados a perceber o quanto idéias como documento e passado devem ser vistas como forças vivas e potentes para a construção e entendimento da história de nossa cultura.

Por outro lado é importante sinalizar, voltando ao documentário de Guzman, a referência explícita ao museu, neste caso de Atacama, como espaço de preservação e documentação da cultura de um povo. No documentário Guzman discute a maneira como os corpos de povos primitivos, seus ossos e crânios são conservados, arquivados e classificados como verdadeiros tesouros da história cultural do povo chileno.

De fato, é impossível negar que o contemporâneo tem sido arrebatado por uma compulsão de pesquisas que giram em torno do arquivo. Vivemos uma febre de arquivo; anseio que abarca desde discussões mais teóricas que colocam em debate o sentido etimológico, filosófico, jurídico e os diferentes sentidos que o termo pode ter no resgate da nossa história - seja ela política, social, etnográfica ou cultural - passando, no campo específico da arte, por debates e práticas que se apropriam da temática em questão.

Exposições baseadas integralmente ou parcialmente por questões que perpassam este conceito, artistas que trabalham com material de arquivo e/ou que discutem metodologias de classificação, arquivologia e museologia, acirradas disputas entre colecionadores privados e museus públicos pela aquisição de obras e arquivos artísticos, até chegar aos debates atuais em torno das políticas de arquivo e acervo institucionais, são apenas alguns dos pontos que podemos citar dentro do contexto específico das artes na contemporaneidade.

Uma primeira questão que poderíamos colocar é: qual seria o motivo ou os motivos desta febre de arquivo que faz parte da contemporaneidade? 
Longe de pretender esgotar o assunto podemos dizer que esta febre de arquivo ou arquivomania tem, em uma primeira instância, relação intrínseca com a chamada crise da história ou, mais particularmente, com o anseio e a necessidade de escrevermos outras histórias para além daquelas ditadas pelo pensamento hegemônico.

Uma das discussões que fazem parte dos acalorados debates da chamada pós modernidade é a ideia de um suposto fim da história; ideia que vem sendo revisitada e debatida por uma série de pensadores seja no campo mais social, político quanto da história da arte.

É dentro desta perspectiva que encontramos pensadores como Walter Benjamin, por exemplo, que combate o conceito iluminista de história propondo alternativas para outra história narrada na contra mão da história dita oficial. Em suas teses "Sobre o conceito de história", ele aponta para a necessidade de se escrever uma história a contrapelo; uma história que, contrariamente às narrativas hegemônicas e oficiais, incorpora exatamente tudo aquilo que é deixado para trás.

Dentro de perspectiva diversa poderíamos enumerar uma série de discussões voltadas ao campo da história e da historiografia da arte que colocam em debate a idéia de um suposto fim. As mais conhecidas são aquelas empreendidas por Hans Belting em seu livro O Fim da história da arte: uma revisão dez anos depois e por Arthur Danto em Após o fim da arte: a arte contemporânea e os limites da história (2006). Independentemente das questões sinalizadas pelos autores, e do fato de eles não proporem alternativas ou métodos historiográficos diversos para o entendimento da prática artística é possível perceber de que tanto um quanto o outro detectam a crise do modelo da história da arte eurocêntrico e o fim de uma tradição.

O que chegou ao fim, para estes autores, é uma pretensa história linear da arte que - de 1400 até o final do modernismo, na primeira metade do século XX - foi inteiramente contada sob um ponto de vista euro-ocidental, como se esta fosse uma cultura única e universal. De um lado esta pretensa universalidade teria sido desmascarada seja pela existência de culturas que estão muito longe de se identificarem com o modelo euro-ocidental, seja por que o modo tradicional de se narrar a história, por meio de estilos e características precisas linearmente, passou a não dar mais conta dos novos desenvolvimentos artísticos que surgiram depois do fim do modernismo no campo das artes. 
É todo um mundo instaurado pelo pensamento hegemônico que se desestabiliza operando-se muitas vezes um processo de reativação de culturas até então descartadas, como é o caso da cultura da América Latina que aparece de fora das histórias ditas oficiais da história da arte e, obviamente, quando aparecem, surgem muitas vezes dentro de recortes epistemológicos que não refletem as particularidades da nossa cultura.

A febre de arquivo aparece precisamente neste contexto, marcada por uma "guerra" entre forças que disputam por uma nova definição geopolítica da arte, reflexo seja do fortalecimento de culturas antes tomadas como periféricas seja da necessidade da construção de "outras" histórias.

\section{PARTE 2}

\section{Deslocamentos do arquivo na arte contemporânea: da passagem do arquivo como documento para o arquivo como poética e dispositivo performático}

Para alguns autores a obra de arte enquanto arquivo, no Brasil, é conseqüência de um processo que surgiu por volta dos anos 60 quando uma série de artistas, muitas vezes marginalizados do sistema oficial das artes, começaram a desenvolver projetos mais experimentais questionando o fetiche do objeto de arte e o sistema das artes daquele contexto histórico (Freire, 2006).

Estas práticas, advindas da arte conceitual - ou melhor, do conceitualismo, para falar de maneira mais ampla - circulavam muitas vezes fora do circuito oficial das artes da época e hoje podem ser encontradas em arquivos particulares de artistas.

De fato o que se percebe é que uma parcela do pensamento crítico e da produção artística produzidos naquele período foi descartada por uma narrativa oficial e hegemônica captaneada por um modelo que se reproduzia conforme os ditames da matriz norte-americana vigente então no país.

Paulo Brusky, como sinaliza Freire (2006), é um dos artistas brasileiros que explicitaram essa relação entre o arquivo, novos meios de circulação no campo das artes e as estratégias críticas contra o objeto de arte e o sistema das artes nos anos 1960. O arquivo de Paulo Brusky reúne atualmente mais de 70 mil itens (produções em arte postal, registros de performances, publicações coletivas, produções em fax arte, entre outras) e pode ser visto como um testemunho das ricas trocas de informações entre artistas e da criação de um circuito de arte paralelo ao circuito oficial das galerias e museus na época. Hoje, 
este arquivo, pode ser visto como uma rica fonte para a construção de novas narrativas sobre a arte conceitual no Brasil.

Mais do que um mero espaço de armazenamento de documentos os arquivos de artista deste período são a expressão de um conjunto de sistema formadores de discurso, mais propriamente das idéias sobre a arte conceitual no Brasil: sobre a maneira como os artistas deste período entendiam o papel do artista e os próprios modos de produção, recepção e circulação da arte.

\section{- Arquivo como poética e modus operandi no contexto da arte contemporânea}

Muitas das práticas artísticas realizadas entre os anos 70 e 90 vão incorporar algumas prerrogativas já delineadas nos anos 60: a preocupação com a desmaterialização do objeto, o interesse pelo desenvolvimento de propostas que incorporam a dimensão do tempo e do processo artístico, o desenvolvimento de projetos que propõem processos diversos de circulação no campo das artes, a utilização de novos meios, a crítica ao sistema da arte (Arantes, 2005).

Muitas destas práticas conduziram os artistas menos por um interesse na produção de um objeto acabado em si mesmo mas na produção de ações em processo das quais se guardavam os seus fragmentos. Estes "restos", vestígios, traços destas produções em processo, efêmeras, desmaterializadas, "in progress", foram registradas, muitas vezes, por dispositivos midiáticos arquivais - fotografias, vídeos, papéis, documentos, imagens das acões, relatos orais, etccomo espécie de testemunho das ações desenvolvidas.

Por outro lado, estes dispositivos arquivais, como o vídeo e a fotografia, por exemplo, foram muitas vezes elementos de criação e produção de linguagem.O vídeo Marca Registrada desenvolvido por Letícia Parente em 1974, em que a artista borda na sola do próprio pé a inscrição Made in Brasil, é um bom exemplo neste sentido. A duração deste vídeo é exatamente o tempo em que a artista demora para fazer a inscrição/escritura na pele de seu corpo. Poderíamos nos perguntar se o vídeo, neste caso, é somente um registro ou documentação da performance realizada pela artista ou se ele é em si mesmo um dispositivo de construção de linguagem; uma videoperformance. Se esta é uma discussão que vai além do escopo pretendido aqui, uma questão é importante destacar: o fato de que existe na contemporaneidade uma intrínseca relação entre obra e arquivo 
em função, entre outros, do advento dos dispositivos midiáticos que são ao mesmo tempo produtores de linguagem e dispositivos de registro.

Dentro deste contexto da produção artística que vai para além da arte objetual e de uma arte da presença, tão característica dentro das diferentes vertentes da arte contemporânea brasileira, os vestígios, traços, documentos residuais passam, em alguns casos, a fazer parte da "operação" intrínseca da própria obra.

Nestes casos não se trata de reduzir a obra a seus documentos e registros, mas de perceber que existe certa operação "arquival" inerente à arte contemporânea em função seja do processo de desmaterialização artística, da incorporação dos novos meios no campo da arte bem como da incorporação da dimensão do tempo e do processo em seu fazer.

Não se trata neste caso de simples paradoxo cultural de preservação, ou seja, de ímpeto de perenizar o transitório e o efêmero que marca profundamente as produções de arte contemporânea, mas do entendimento de que determinados aspectos da obra de arte contemporânea - que dialogam com a dimensão do tempo, do efêmero e do transitório - incorporam certa dimensão sintomática e lacunar - diria Jacques Derrida - como operação intrínseca ao seu fazer. Poderíamos nos arriscar a dizer que a "necessidade de se registrar o evento e de reunir documentos de sua existência levou à descoberta do arquivo como uma modalidade topológica concreta da própria obra" (Costa 2008).

Outro exemplo, neste sentido, é o trabalho do taiwanês Tehching Hsieh apresentado na 30. a Bienal de São Paulo. O artista raspou seus cabelos em 11 de abril de 1980 e iniciou aquilo que seria sua segunda Performance de Um Ano. Naquela época, já vivendo por seis anos como imigrante ilegal nos EUA, o artista vestiu um macacão de operário e registrou em um relógio de ponto cada hora de 365 dias, até 11 de abril de 1981. A obra é apresentada por fileiras de fotografias diárias que serviram como registro da ação do artista, os cartões e o próprio relógio de ponto; os documentos originais do trabalho e uma projeção em $16 \mathrm{~mm}$ que mostra de forma acelerada a passagem do tempo por meio de retratos de Tehching. Neste trabalho a fotografia não é somente um dispositivo de registro, mas elemento fundamental da própria obra que pode ser interpretada como uma espécie de fotoperformance. 


\section{PARTE 3}

Não por acaso é possível detectar uma série de manifestações na arte contemporânea em que a questão do arquivo torna-se eixo fundamental.

A questão do arquivo vem sendo discutida, por exemplo, em práticas da artista brasileira Rosângela Rennó. Ela trabalha com registros e documentos e faz com que as imagens de arquivo ganhem nova dimensão. Suas fontes de inspiração como jornais, álbuns de família, bibliotecas, arquivos mortos, são matérias para a construção de algo vivo.

Em Vulgo, Rennó trabalha com material de arquivo pertencente à Penitenciária do Estado de São Paulo, composto por material fotográfico que pretendia identificar os prisioneiros por número, características físicas (feições, cor da pele, altura, peso e deformidades corporais) e marcas (tatuagens e cicatrizes propositais ou acidentais).

Em nenhuma das imagens está visível o rosto do fotografado, a maioria focalizando apenas a nuca e o couro cabeludo dos modelos. A intervenção digital da artista se restringe (pelo menos aparentemente) a uma coloração vermelha clara acrescentada justamente no centro do redemoinho do couro cabeludo de cada indivíduo.

\section{8 de 14.000, de Alice Micelli}

Dentro de perspectiva semelhante podemos citar o trabalho da artista brasileira Alice Micelli: 88 de 14000 que apresentei na curadoria Crossing no Paço das Artes em 2010.

O projeto é um vídeo formado por 88 retratos de identificação, selecionados pela artista no arquivo fotográfico da antiga prisão S-21, em Phnom Penh, capital do Camboja, onde 14 mil pessoas, entre homens, crianças e mulheres, foram executadas pelo regime do Khmer Vermelho. No trabalho, as imagens dos 88 prisioneiros mortos são projetadas em uma cortina de areia, de acordo com o tempo vivido por cada um dentro da prisão: um dia de vida na prisão equivale a um quilo de areia, o que significa quatro segundos de visibilidade no vídeo.

Neste projeto, a artista trabalhou com negativos originais que hoje estão no Museu do Genocídio no local da antiga prisão no Camboja. A partir destes negativos, fez ampliações e registrou, em vídeo, as fotografias projetadas sobre 
uma cortina de areia. As fotografias originais foram tiradas, como nos relata a artista, instantes antes da morte dos retratados: "estas pessoas sabiam, no momento em que sua fotografia era tirada, que iriam morrer, senão instantes depois da fotografia, certamente poucos meses depois", sinaliza a artista (Arantes, 2010, p. 71-73).

O trabalho é um duplo testemunho: o testemunho que a artista esteve lá e que pode ter acesso aos arquivos e o testemunho, exposto para o público, das barbáries cometidas na história. Neste sentido funciona como uma espécie de válvula contra o esquecimento de situações e arquivos que muitas vezes são soterrados na nossa história.

\section{Meta4walls de Lucas Bambozzi}

Outro artista que trabalha com material de arquivo, mas colocando em debate as questões dos arquivos eletrônicos e digitais, é Lucas Bambozzi. Em Meta4walls, projeto de net art apresentado na XXV Bienal Internacional de São Paulo, o artista desenvolve uma espécie de metalinguagem sobre questões que permeiam o ciberespaço, mais particularmente, sobre os processos de vigilância e invasão de privacidade presentes na rede.

O projeto disponibiliza ao público um arquivo de lixo eletrônico que o artista recebeu sob a forma de SPAMs - mensagens não solicitadas- desde 1999. São mensagens de todo o tipo: links ilícitos, links pornográficos, links de venda de diplomas falsos; ou seja links que colocam em evidência o submundo do espaço virtual e que todos nós recebemos sem prévia autorização diariamente em nossas caixas de mensagem.

\section{Dentro e fora do tubo, de Maurício Dias e Walter Riedweg}

Dentro de outra perspectiva poderíamos citar aqueles projetos que trazem para o espaço público testemunhos pessoais e/ou arquivos pessoais. Para além do monumento tradicional, que são geralmente construídos para comemorar um acontecimento socialmente importante ou para homenagear uma pessoa ilustre, estes projetos, desenvolvidos no espaço público, podem ser lidos como espécie de monumentos que dão voz à pessoas "comuns" para a compreensão e edificação de nossa história.

Dentro desta perspectiva encontramos o projeto Dentro e fora do tubo (1988) desenvolvido por Maurício Dias e Walter Riedweg. Realizado a partir de 
depoimentos gravados com refugiados vindos de terras em conflito, e vivendo na Suíça à espera de legalização de seu asilo político, a idéia do trabalho - a partir de uma intensa convivência com o grupo dos depoentes - foi a de gravar depoimentos orais da memória do trajeto que o imigrante realizou quando da saída de sua cidade natal até chegar à Suíça. Estas lembranças, vozes, memórias dos refugiados, testemunhos, foram colocados em walk-talks e espalhados, dentro de tubos, no espaço urbano, disponíveis para a escuta da população. Trata-se, neste caso, de colocar em evidência, no espaço público, estados afetivos decorrentes de situações específicas vinculadas aos processos de marginalização.

\section{O Canto das Sereias, Claudio Bueno}

Ainda dentro desta linha podemos lembrar do projeto do artista brasileiro Claudio Bueno, O Canto das Sereias, uma espécie de monumento sonoro e invisível, instalado no antigo porto de Québec (Canadá): trata-se de uma homenagem a 8 mulheres canadenses que morreram no mar, trabalhando com rádio-difusão, nos navios da primeira e da segunda guerra mundial.

A idéia do projeto foi a de fazer uma espécie de homenagem a estas mulheres através de uma performance sonora realizada na margem do rio Saint-Laurent por cantoras convidadas pelo artista. A performance sonora pode ser ouvida se nos aproximarmos das margens do rio, com um aplicativo para celular. $O$ trabalho, diz o artista, "lida com um modo de hackear a história da cidade. Contar de um outro jeito, reescrever poeticamente e criticamente, ou até mesmo, ficcionalizar - sem precisar de muitas permissões. Seja um modo de contar mais poético ou que desvie da política tradicional de criação de monumentos instalado em nosso celular" (e-mail Jul. 2012).

\section{Conclusão}

Em um momento em que a história , e mais precisamente a história da arte tem sido revisitada, nada mais natural que debates sobre como a história da arte é construída - quais são os seus documentos, qual é a sua base documental, que arquivo é este que tem servido de base para sua formação - venham a tona.

A questão do arquivo, inclusive em um momento de abertura dos arquivos da ditadura militar no Brasil, tem feito parte de uma faceta da produção da arte brasileira que não somente coloca em debate a importância do resgate dos arquivos artísticos para a construção de outras narrativas no campo da história 
da arte mas também a visão de que o arquivo, e portanto a história, esta sempre aberta a outros significados possíveis.

Se, como nos fala Jacques Derrida, é impossível reconstruir a história em sua totalidade, pois o arquivo é sempre lacunar e sintomático, por outro, cabe a nós, historiadores, pesquisadores, artistas, curadores, editores, gestores, estudantes, percorrermos nossos arquivos no sentido de contribuir para a edificação de nossa história.

\section{Referências}

ARANTES, Priscila. Arte e Mídia: perspectivas da estética digital. São Paulo: Editora Senac/SP, 2005.

ARANTES, Priscila. Diálogos entre Vilém Flusser e Fred Forest. Flusser Studies 08 - May 2009. Versões em português e inglês disponíveis em http://www.flusserstudies.net/archive/flusser-studies-08-\%E2\%80\%93-may2009. Acesso em: 04 mai. 2014.

ARANTES. Priscila. Crossing [Travessias]. Org. e curadoria. São Paulo: Imesp, 2010.

ARANTES, Priscila. Livro/Acervo (Org). São Paulo: Imesp, 2010.

BELTING, Hans. O fim da história da arte: uma revisão dez anos depois. São Paulo: Cosac Naify, 2006.

BENJAMIN, Walter. Magia e Técnica, Arte e Política. Obras escolhidas. Trad.Sérgio Paulo Rouanet. V.1, 6a ed. São Paulo: Brasiliense, 1993.

COSTA, Luiz Claudio da. Registro e arquivo na arte: disponiblidade, modos e transferências fantasmática de escrituras. Anais do $17^{\circ}$ Encontro Nacional da ANPAP, p. 388-397, 2008. Disponível em: http://www.anpap.org.br/anais/2008/artigos/037.pdf Acesso em: 04 mai. 2014.

DANTO, Arthur. Após o fim da arte: a arte contemporânea e os limites da história. São Paulo: Odyssens Editora, 2006.

DERRIDA, Jacques. Mal de arquivo: uma impressão freudiana. São Paulo: Relume Dumará, 2005.

FREIRE, Cristina; LONGINA, Ana (Org). Conceitualismos do Sul/Sur. São Paulo: Annablume, USP.MAC-AECID, 2009.

FREIRE, Cristina. Arte Conceitual. Rio de Janeiro: Jorge Zahar, 2006. 